\title{
NPL Training: delivering measurement skills
}

\author{
André Silva ${ }^{1, a}$ and Suzanne Wells ${ }^{1, b}$ \\ ${ }^{1}$ National Physical Laboratory (NPL), Hampton Rd, Teddington, Middlesex TW11 OLW, United Kingdom.
}

\begin{abstract}
Résumé. Ce papier décrit les nombreux défis dus à la baisse des compétences dans le domaine de la mesure. Il analyse les facteurs situés au cœur de la question, identifie les réponses apportées par le National Physical Laboratory (NPL) et décrit l'impact de ces activités à différents niveaux. Au travers d'une initiative menée par le NPL, l'institut national de métrologie du Royaume-Uni, et en collaboration avec le monde universitaire et le secteur industriel, ce papier espère apporter une solution pérenne à ce problème.
\end{abstract}

\section{Decline in metrology skills: the background}

As an infratechnology [1] enabling and underpinning technological innovation, science and research, metrology (the science of measurement) has proven that its impact extends well beyond economic activity [2]. The ability to understand and apply measurement knowledge across the major growth sectors of the UK economy is vital, and has a direct impact on global competitiveness and productivity. Nevertheless, the UK's National Physical Laboratory (NPL) has been gathering feedback from industry and academia regarding the increasing lack of metrology knowledge and skills. Organisations have been reporting a decline in measurement skills caused by variety of factors, such as:

- General lack of skills in Science, Technology, Engineering, and Mathematics (STEM): a skills shortage is reflected in the UK's Tier 2 shortage occupation list. This reveals the increase in demand for STEM skills, which outstrips the potential supply in the short term. STEM related jobs dominate the list, including a range of job titles and job roles under Physical Scientist occupations [3].

- Lack of training offering: this is noticeable in formal metrology education in academic and vocational qualifications, as well as within workplace learning schemes. This leads to difficulties recruiting staff with specialist metrology skills [4].

- Low training take-up: 44\% of UK's employees received no training [5], even though independent reports suggest that, for the UK engineering workforce to have worldclass skills, there is an immediate upskilling requirement [6]. In regard to metrology-related training, recent reports shown that $35 \%$ of practitioners have not received any training and development initiatives within the last 12-24 months [4].

- Low training budget: statistics show that the majority of managers spends less than $10 \%$ of their overall training budget on metrology-related training and development, with $11 \%$ stating that they do not spend any of their budget on metrology-related training and development initiatives [4].

- Demographic factors: key measurement skills are being lost as the skilled population is reaching retirement age. A Royal Academy of Engineering report on 'jobs and growth', forecasts that, between 2012 and 2020, the UK economy will require 830,000 professional scientists, engineers and technologists, largely to replace those leaving engineering practice (e.g. through retirement).

Together, these factors provide evidence of existing skills gaps and skills shortages in industry and academia. Furthermore, evidence [4] shows that this adverse impact is not only being reflected on productivity, quality and technical development; it is also adversely affecting employees' confidence, and increasing stress in the workplace.

In summary, this is a multidimensional challenge, which requires the creation of formal (nationally recognised) education and training programmes, adequately covering metrology topics within existing STEM courses, apprenticeships, and workplace learning schemes. This will enable the provision of a pipeline of skilled engineers and metrologists across industry sectors.

\footnotetext{
a André Silva: andre.silva@npl.co.uk, ${ }^{b}$ Suzanne Wells: suzanne.wells@npl.co.uk
} 


\section{UK's NMI bridging the metrology skills gap}

\subsection{NPL's measurement skills agenda}

The Department for Business, Innovation and Skills (BIS) invests around $£ 70$ million each year to make measurement more accurate for UK business and citizens, and a large part of this work is carried out by NPL, the UK's National Metrology Institute (NMI). NPL is a world-leading centre in developing and applying the most accurate measurement standards, science and technology available. For more than a century, NPL has developed and maintained the nation's primary measurement standards, which underpin an infrastructure of traceability throughout the UK and the world ensuring accuracy and consistency of measurement.

NPL has been actively involved in the measurement skills agenda, delivering knowledge products, training and outreach programmes to schools, colleges, industry and academia. The impact of this engagement is tangible through activities and projects such as:

- The Outreach Programme: which engages national schools and colleges in a range of metrology focused outreach activities across the UK.

- The Advanced Apprenticeship Scheme: through the intake of our own apprentices, enabling them to work alongside world-leading metrologists, scientists, and other professionals across the laboratory within a unique translational research environment.

- The Product Verification Programme: helping companies manufacture products to original design specifications through better measurement and inspection practices. This programme places the need for measurement skills at its heart, and aims to underpin the success of manufacturing supply chains.

- The Measurement Skills for Industry Programme: which established a Metrology Training framework as a mechanism to make its measurement expertise available to professionals and students looking at improving corporate measurement capability.

\subsection{NPL Training and the measurement skills for industry programme}

NPL Training was founded to deliver world-leading measurement knowledge, skills, products and services, which are critical to industrial research, development, and to support UK's business success.

Designing and delivering metrology training programmes for almost 10 years, NPL Training now offers a varied product portfolio. This covers a range of educational solutions which emphasise the importance of metrology, encompass advancements in measurement science, and support the application of good measurement practices. All this is available to a global audience over a wide variety of learning methodologies, and caters for a range of diverse learning styles. NPL Training is currently delivering measurement skills via the following mechanisms
- Framework of National Qualifications in Metrology Classroom Training Courses (2006 - present): a workplace learning framework under the UK's Qualifications and Credits Framework (QCF). This offers National Qualifications in Metrology through practical, application-based, classroom training courses, designed to improve skills and competencies in measurement. These courses range from basic to expert levels of knowledge, and cover the topics of Metrology, Uncertainty, Dimensional Measurement, and Laser Safety. Some training courses were also launched as Continuing Professional Development (CPD) units, delivering skills in Temperature Measurement \& Calibration, Humidity Measurement \& Calibration, Instrumentation \& Sensors, Lamp \& LED Safety, and Reference Dosimetry.

- e-Learning Training Programme (2013 - present): a series of online CPD courses, that range from basic to intermediate levels of knowledge in the topics of Metrology, Uncertainty, Dimensional Measurement, and Radioactivity Measurement / Nuclear Medicine. This series is composed of step-by-step video lessons, printable slides, self-paced exercises, assessment, and a wide selection of additional content. NPL was the first NMI to offer e-learning training solutions optimised for mobile devices to a worldwide audience. These courses are accessible across multiple devices, allowing training on demand, and at the learners' own convenience. Compared to traditional training, e-learning is much more flexible, allowing trainees to take easily-digestible courses in their own time and at their own pace.

- Measurement Explained Series (2014 - present): a series of free online CPD open units, introducing the basic principles of metrology across the measurement sciences, making metrology knowledge affordable, available, and easily accessible. These units are ideal precursors to NPL's certified e-learning courses. This solution is selfpaced and accessible across different devices.

- Framework of National Qualifications in Metrology Blended Learning Courses (2015 - present): a new series of accredited training courses mixing the advantages of self-paced online training, such as increased flexibility, with the benefits of hands-on practical application. The blended-learning methodology refers to the teaching / learning method, comprising face-to-face and e-learning components. e-Learning replaces classroom 'theory or knowledge' components, partly allowing training on demand, and at the learners' own convenience. Some courses within this framework offer National Qualifications in Metrology.

- Bespoke Training support (2006 - present): this is delivered through the provision of tailored training programmes to match the skills needs of specific customers, helping them to outline and develop their own metrology training programmes. NPL's longstanding engagement with worldwide industry leaders, covering a wide range of sectors, technologies and applications, demonstrates that although customers' requirements and manufacturing techniques have changed over the years, the need for accurate measurements remains as relevant as ever. 
It is crucial to note that NPL's positioning is not to replicate, or replace education establishments. Instead, NPL intends to add value in the transfer of specialist metrology knowledge, and where required, provide the 'tools of change' to organisations, giving them the necessary skills to lead their own metrology programmes. The understanding of NPL's distinctive purpose relies on the identification of a number of characteristics that make it unique, such as:

- NPL's longstanding interactions with both academic and industrial partners, providing them with expertise and support in measurement matters.

- NPL's proven content development framework, which taps into the knowledge of its 500+ metrologist workforce, which takes part in the development, quality control, and delivery of training materials.

- NPL's uniqueness in developing metrology training programmes, which lies in its ability to bring together learning theory and technical know-how. This delivers pedagogical quality assurance, and overall quality control to any educational / training project.

\section{NPL Training: delivering measurement skills}

\subsection{Engagement mechanisms}

NPL Training delivers measurement skills to schools, colleges, universities and industrial workplace learning schemes. Its training product portfolio is being delivered via a number of mechanisms, including:

- Direct delivery to industry: through classroom training courses at NPL and / or on client sites; and through a unique online / mobile learning platform.

- Indirect delivery to industry: through an approved third party delivery network including Coventry University and Hexagon Metrology; a 'train the trainer' programme which equips in-company trainers with essential skills and confidence to deliver accredited metrology training.

- Direct engagement with academic and vocational institutes: through the integration of scientific lectures and training modules within selected UK's Higher Education Institutions (HEI) (reaching undergraduates, postgraduates, and apprentices within industrial apprenticeship schools); and through project placements and postgraduate research at NPL.

- Direct engagement with schools, colleges and the general public: though a coordinated programme of Outreach Activities, such as the NPL Academy, which sees the intake of more than 50 students per year (Levels 2 and 3 ).

\subsection{Measurable impact in industry}

Between 2013 and 2014, NPL Training delivered metrology courses to over 1,500 learners. In addition, one year after launch, approximately 1,300 learners signed up to NPL's Learning Management System. During the same period, NPL Training has supported 500+ companies from a wide range of sectors, including: aerospace, defence, security, automotive, advanced manufacturing and healthcare. This ongoing effort has been recognised, as $92 \%$ of organisations attending measurement training have seen improvements in their organisation following these training courses [8].

NPL Training's product portfolio is now being delivered in over 90 countries.

\subsection{Academic engagement}

Our continued engagement with academia has shown that the quality, quantity, and level of metrology subject matter within academic and vocational qualifications varies greatly. This can lead to graduates entering industry without the required measurement skills.

In light of this, NPL has been engaging with strategic academic institutions in an attempt to bring formal metrology knowledge into their existing programmes. The objective is to provide students with early career options within engineering, physics, and other sciencerelated degrees. This will help delivering a pipeline of skilled metrologists to industry.

\subsection{Supporting the wider impact}

NPL Training's involvement in the measurement skills agenda supports NPL in being an essential part of the highly productive Intermediate Research and Technology Sector, which contributes at least $£ 3$ billion per annum to UK GDP and supports over 60,000 jobs; enabling the transfer of measurement knowledge to organisations through the implementation of measurement improvement actions (emphasising good practice), driving them towards new or enhanced processes or products; assisting organisations leading measurement innovation activities, which helps them achieve financial benefits of $£ 634$ million per annum [8]. By doing so, NPL and NPL Training are contributing so that a single year of NMS funding helps business to achieve annual financial benefits of $£ 712$ million.

\section{The need to raise the profile of measurement training}

\subsection{Sustaining an industry-led competency framework}

NPL now places over 100 years of knowledge and expertise at the disposal of a worldwide audience, in the form of an extended portfolio of educational / knowledge products. NPL's longer term aim is to raise awareness of the importance and benefits of metrology skills, and to work towards recognised career paths and professional recognition of the metrology skill set. Until this is achieved, NPL training is:

- Guiding apprentices and professionals through certified and accredited metrology learning pathways, which can take them from elementary to advanced levels of knowledge and skill sets. 
- Delivering quality metrology content produced by world-leading scientists, synthesising complex subjects into simple, easy to understand learning materials.

- Offering a range of training options to learners, partly or fully releasing them from time and location restrictions, reducing the time away from the job, saving travel costs, and fitting training into busy work schedules.

Nevertheless, although NPL is positioned at the heart of the national metrology skills agenda (and NPL Training is implementing its Measurement Skills for Industry Programme), the multidimensional issue identified at the start of this article still stands as an exciting challenge. It is NPL's role to keep on working with industry partners, professional institutions, skills bodies and education establishments to define, create and deliver a range of training programmes that will develop applied metrology skills, for learners at all stages of their career.

For this reason, we are currently championing the development of an Apprenticeship Programme for Applied Metrology Skills, working with industrial and academic partners. If successful, NPL is ready to take the lead in this initiative, work with employers, and other organisations to support the development of an Industrylead Competency Framework, which will reflect national (and international) industry needs. This will lay the foundation to a shared challenge, and help place industry requirements at the heart of academic and vocational qualifications, workplace learning schemes, and industrial apprenticeships.

Disseminating knowledge, transferring state-of-the-art expertise, and increasing measurement skills and competence is integral to NPL Training. We are committed to collaboratively generate solutions to shared challenges, and to help provide the right tools to empower teachers, trainers, employers, learners, employees, and the next generation of skilled metrologists.

\section{References}

1. A. Estibals. Infratechnologies: the building blocks of innovation-based industrial competitiveness. Nesta. (2012) Retrieved July, 2015, from http://www.nesta.org.uk/publications/infratechnologi $\underline{\text { es }}$

2. G. Williams. The assessment of the economic role of measurements and testing in modern society. Pembroke College, University of Oxford. (2002)

3. UK Visas and Immigration. Sponsorship: guidance for employers and educators and Immigration and borders: Tier 2 Shortage Occupation List Government-approved version valid from 6 April 2015. (2015) Retrieved July, 2015, from https://www.gov.uk/government/publications/tier-2shortage-occupation-list

4. K. Saliba. Metrology Apprenticeship Survey: Executive Summary Report. Unpublished Manuscript, National Physical Laboratory, Teddington, UK. (2014)
5. UKCES. UK Commission's Employer Skills Survey 2011: UK Results. IFF Research. (2012) Retrieved on November 07, 2012: http://www.ukces.org.uk/publications/employerskills-survey-2011

6. Semta. Engineering Sector Factsheet 2011- UK Reports (9 regions). (2011) Watford: Semta.

7. M. Harrison. Jobs and growth: the importance of engineering skills to the UK economy (Royal Academy of Engineering econometrics of engineering skills project). The Royal Academy of Engineering. (2012) Retrieved July, 2015, from http://www.raeng.org.uk/publications/reports/jobsand-growth

8. National Physical Laboratory. Customer Survey. (2012) Retrieved July, 2015, from http:/www.npl.co.uk/publications/customer-survey/ 